\title{
Germination and storage of recalcitrant seeds of some tropical forest tree species
}

\author{
F. Corbineau* and D. Côme*
}

Laboratoire de Physiologie des Organes Végétaux après Récolte, CNRS, Meudon, and Université Pierre-et-Marie-Curie (Paris VI), Paris, France

Introduction

Seeds have been termed orthodox or recalcitrant by Roberts (1973) to describe their storage behavior. Orthodox seeds tolerate dehydration down to 5-10\% (dry weight basis) without damage. Prepared in this manner, these seeds can be stored for long periods and their viability can be prolonged at the lowest temperature and moisture content possible. Recalcitrant seeds are highly hydrated and they cannot withstand intensive desiccation. They originate predominantly from tropical or subtropical tree species. These seeds can only be stored in wet medium to avoid desiccation injury and at relatively warm temperature, since most of them are sensitive to chilling (King and Roberts, 1979).

The aim of the present study was to analyze the germination of some recalcitrant seeds of tropical forest trees, and the effects of dry and wet storage on their viability.

\section{Materials and Methods}

Experiments were carried out with seeds of two Dipterocarps collected in Thailand at the Phu Khac Botanical Garden (Shorea roxburghii) and the Meak Lek Arboretum (Hopea odorata), and seeds of Simarouba amara (Simaroubaceae) and Symphonia globulifera (Guttiferae) collected in the dense forest near Kourou, French Guiana.

Germination tests were performed in darkness, at temperatures between 5 and $35^{\circ} \mathrm{C}$, on cotton wool saturated with deionized water and placed in plastic rectangular boxes $(18 \mathrm{~cm}$ long $\times 12 \mathrm{~cm}$ wide $\times 5.5 \mathrm{~cm}$ deep). $50-100$ seeds were used in each test (10-25 seeds per box).

To study the effect of dehydration on viability, seeds were placed in open air at $20^{\circ} \mathrm{C}$ and $55 \%$ relative air humidity. Samples were periodically removed, weighed and placed for germination at $30^{\circ} \mathrm{C}$. Viability was expressed by the maximal germination percentage. Moisıuia content was calculated on a fresh weight basis.

Wet storage was performed at $5,8,10,12$, 15 and $20^{\circ} \mathrm{C}$, on cotton wool imbibed with deionized water after seed treatment with quinolate (copper oxyquinoleate). Viability was periodically tested by transferring seeds to $30^{\circ} \mathrm{C}$.

All results concern seeds visually healthy at harvest time.

\footnotetext{
* New address: Laboratoire de Physiologie Végétale Appliquée, 4, pl. Jussieu, Tour 53, 75230 Paris Cedex 05 , France.
} 


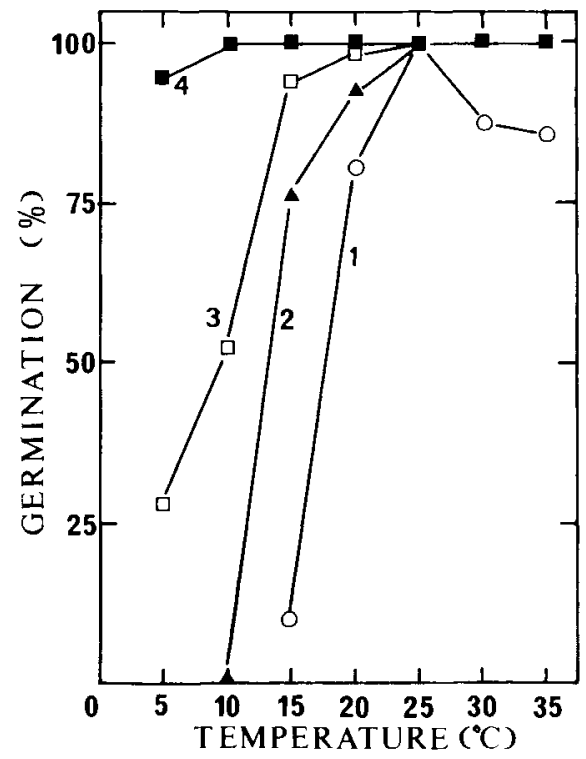

Fig. 1. Effect of temperature on the germinative capacity of Simarouba amara (1). Symphonia globulifera (2), Shorea roxburghii (3) and Hopea odorata (4) seeds.

\section{Results}

Germination of freshly harvested seeds

Freshly harvested seeds had no dormancy. In all cases, germination was best at relatively high temperatures (optimum at $25-30^{\circ} \mathrm{C}$ ) (Fig. 1). Below $15^{\circ} \mathrm{C}$, it was reduced (Shorea roxburghii) or impossible (Symphonia globulifera and Simarouba amara), but Hopea odorata seeds germinated even at $5^{\circ} \mathrm{C}$.

\section{Effect of dry storage}

Initially, the mean moisture content of seeds was relatively high: $67 \%$ for Symphonia globulifera, $39 \%$ for Simarouba amara, $33 \%$ for Hopea odorata and $26 \%$ for Shorea roxburghii. All seeds were dead when their mean moisture contents decreased to about $8 \%$ for Simarouba amara, $15 \%$ for Shorea roxburghii and

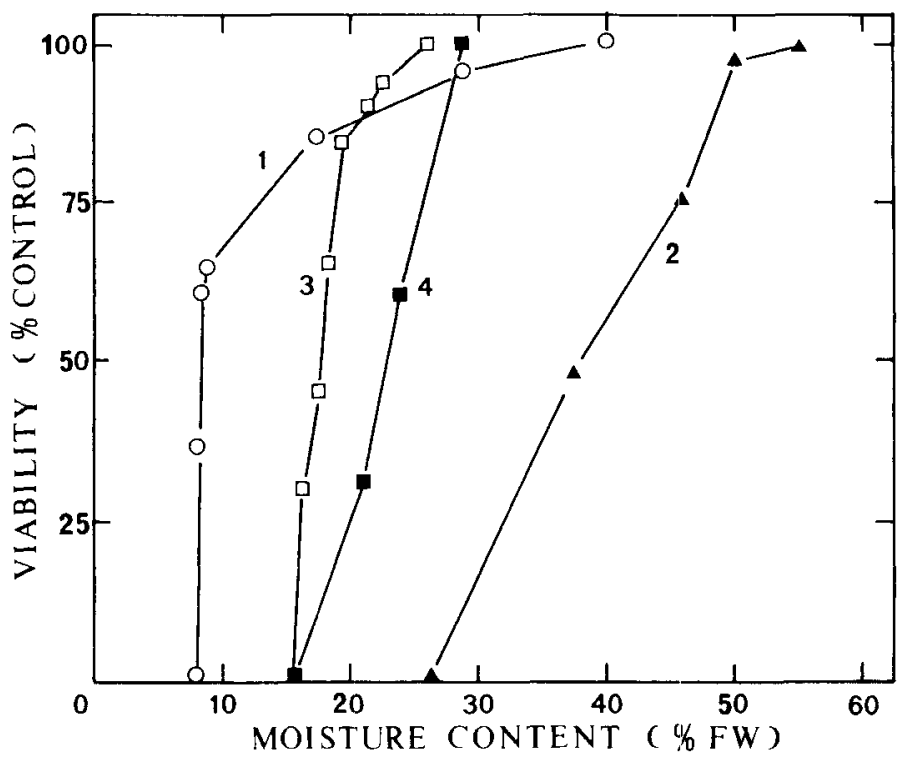

Fig. 2. Relation between moisture content (fresh weight basis) and viability of Simarouba amara (1), Symphonia giobulifera (2), Shorea roxburghii (3) and Hopea odorata (4) seeds. 
Hopea odorata and $26 \%$ for Symphonia globulifera (Fig. 2). Simarouba seeds remained viable at relatively low moisture content, but they produced abnormal seedlings.

\section{Effects of wet storage}

Seeds often started to germinate during storage. Moreover, seeds or seedlings were easily injured by chilling when the temperature decreased below $10^{\circ} \mathrm{C}$ for Shorea roxburghii, $15^{\circ} \mathrm{C}$ for Symphonia globulifera and $20^{\circ} \mathrm{C}$ for Hopea odorata and Simarouba amara (Fig. 3). At temperatures that do not result in chilling injury, seedling growth was too fast to allow extended storage. Storage duration did not exceed 2-3 months except for Symphonia globulifera $\left(2-3 y\right.$ at $\left.15^{\circ} \mathrm{C}\right)$.

\section{Discussion and Conclusion}

Seeds of Shorea roxburghii, Hopea odorata, Symphonia globulifera and Simarouba amara are not dormant and, as for many other tropical species (Côme, 1982), they germinate easily at high temperatures. However, seeds of Hopea odorata are also able to germinate at relatively low temperatures $\left(5^{\circ} \mathrm{C}\right)$. They are highly hydrated and lose viability when the moisture content decreases. They are typical recalcitrant seeds whose sensitivity to desiccation depends upon the species (King and Roberts, 1979; Corbineau and Côme, 1988). Dry storage is impossible and wet storage is difficult, because the temperature must be low enough to prevent germination or reduce the rate of seedling growth, but a relatively low temperature is linked to a risk of chitling injury. So far, long-term storage methods for recalcitrant seeds of tropical forest trees do not exist. Use of solutions with a

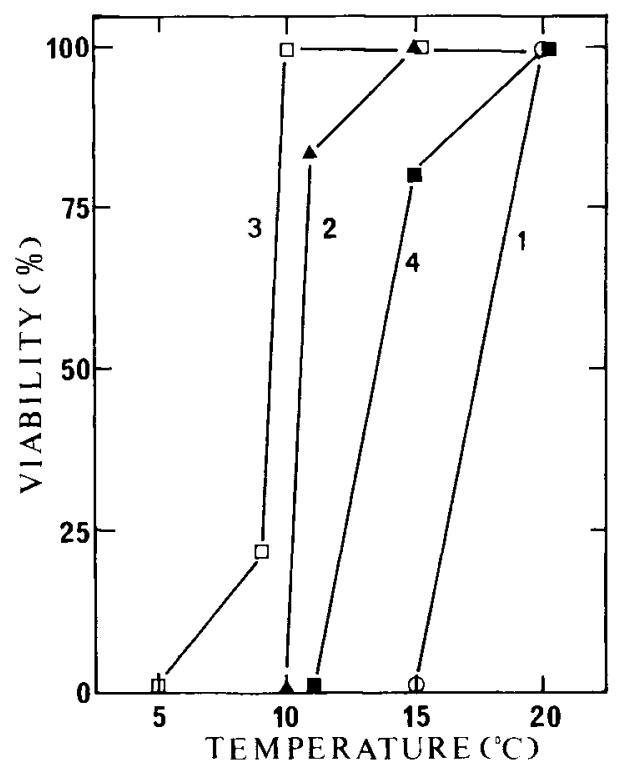

Fig. 3. Effect of temperature of wet storage on viability of Simarouba amara (1). Symphonia globulifera (2), Shorea roxburghii (3) and Hopea odorata (4) seeds.

suitable osmotic pressure to avoid germination and growth or of cryoprotective agents to enable seeds or young seedlings to withstand low storage temperatures are perhaps possible approaches to increase storage life.

\section{References}

Côme D. (1982) Germination. In: Croissance et Développement. Physiologie Végétale II (P. Mazliak ed.), Hermann, Paris, pp. 129-225

Corbineau F. \& Côme D. (1988) Storage of recalcitrant seeds of four tropical species. Seed Sci. Technol. 16, 97-103

King M.W. \& Roberts E.H. (1979) The storage of recalcitrant seeds. Achievements and possible approaches. International Board for Plant Genetic Resources, Rome

Roberts E.H. (1973) Predicting the storage life of seeds. Seed Sci. Technol. 1, 499-514 